Research Article

\title{
Simple Label-Free Electrochemical Immunosensor in a Microchamber for Detecting Newcastle Disease Virus
}

\author{
Luyen Thi Tran, ${ }^{1}$ Thinh Quang Tran, ${ }^{2}$ Ha Phu Ho, ${ }^{3}$ Xuan Thi Chu, ${ }^{4}$ and Tuan Anh Mai ${ }^{2}$ \\ ${ }^{1}$ School of Chemical Engineering, Hanoi University of Science and Technology, No. 1 Dai Co Viet Road, Hai Ba Trung District, \\ Hanoi, Vietnam \\ ${ }^{2}$ Laboratory for MEMS/NEMS Technology, National Center for Technological Progress, 25 Le Thanh Tong Street, \\ Hoan Kiem District, Hanoi, Vietnam \\ ${ }^{3}$ School of Biotechnology and Food Technology, Hanoi University of Science and Technology, No. 1 Dai Co Viet Road, Hai Ba \\ Trung District, Hanoi, Vietnam \\ ${ }^{4}$ International Training Institute for Materials Science, Hanoi University of Science and Technology, No. 1 Dai Co Viet Road, Hai Ba \\ Trung District, Hanoi, Vietnam
}

Correspondence should be addressed to Tuan Anh Mai; mtuan@itims.edu.vn

Received 7 March 2019; Accepted 7 August 2019; Published 9 October 2019

Guest Editor: Jakub Zdarta

Copyright (C) 2019 Luyen Thi Tran et al. This is an open access article distributed under the Creative Commons Attribution License, which permits unrestricted use, distribution, and reproduction in any medium, provided the original work is properly cited.

In this study, a simple, label-free, electrochemical immunosensor system, including a three-electrode transducer and a microchamber, was designed, fabricated, and integrated with focus toward the detection of Newcastle disease virus (NDV). The chicken egg yolk antibodies (IgY) against NDV were used as the biological recognition element, replacing purified IgG antibodies that require a complex extraction process and time-consuming. The IgY against NDV was immobilized on the sensor surface using PrA/GA and SAM/NHS approaches. The immunosensor showed high sensitivity with NDV concentrations ranging from $10^{6}$ to $10^{2} \mathrm{EID}_{50} / \mathrm{mL}$ with good specificity, repeatability, and small standard deviations. Compared to traditional methods, the immunosensor with advantages such as simple fabrication, quick response, direct detection, and possibility for miniaturization by integrating the immunosensor with the microchamber is potential for applications in contamination studies and field measurements.

\section{Introduction}

Newcastle disease (ND) is one of the most contagious diseases in poultry that has widely spread in South East Asian countries including Vietnam and causes severe economic losses $[1,2]$. So far, the conventional qualitative methods such as hemagglutination inhibition (HI) [2], agar gel precipitation [3], and Latex agglutination tests [4] have been introduced for clinical diagnosis of ND. In addition, enzymelinked immunosorbent assay (ELISA) [2], polymerase chain reaction (PCR) [5, 6], and immunofluorescence test [7] have also been used for the semiquantitative analysis. Although these methods effectively determine NDV in infective samples, they require complicated procedures for sample preparations, sophisticated instruments for assays, and large periods of time for the completion of the assays. Therefore, alternative methods that offer a simple, rapid, and costeffective analytical strategy and possible on-site and in-field measurements are essential.

Label-free electrochemical immunosensor detects antigens using specific antibodies immobilized on a surface of metallic electrodes [8-11]. This method has been developed with rapid analysis, high sensitivity, and portability purposes [12-15]. In this work, the three-electrode setup including the integrated $\mathrm{Au}$ electrodes consisted of a working electrode (WE), a counter electrode (CE) in a chip, and a quasireference $\mathrm{Ag} / \mathrm{AgCl}$ electrode ( $\mathrm{qRE}$ ) was designed and fabricated. The polydimethylsiloxane- (PDMS-) based microchamber was bonded with the integrated three-electrode setup to facilitate miniaturization of the analytical system, and thus, the volume of the consumed biological sample is reduced. Moreover, this structure also simplifies the microelectrode 


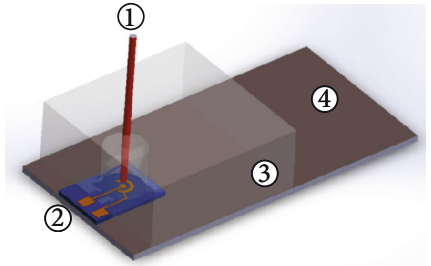

(1) $\mathrm{Ag} / \mathrm{ACl}$ wire (3) PDMS

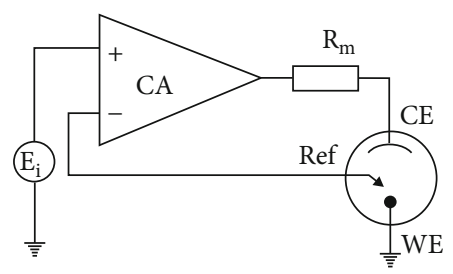

WE: working electrode Ref: reference electrode CE: counter electrode CA: control amplifier

(b)

FIgURE 1: (a) Schematic illustration of the measuring setup and (b) equivalent circuit of the measuring system.

fabrication process in a clean room and, on the other hand, is convenient for electrical connection with a measuring circuit.

In immunosensor development, most of the studies, using monoclonal immunoglobulin G (IgG) antibody from mammalian blood as the biological recognition element, have been focused on antibody immobilization methods to improve the sensitivity, response time, and detection limit [16-18]. However, IgG antibody production and purification require modern techniques, expensive biologicals, long time, and complicated procedures $[19,20]$. In our previous work [21], chicken egg yolk immunoglobulin (IgY) antibody was used as an alternative to IgG in immunosensor fabrication. The immobilization using IgY antibody offers advantages with respect to cost-effective and rapid detection of virus in infectious disease outbreaks. In addition, it is less dependent on purified IgG sources with shorter lease time and reduced costs. In this work, chicken egg yolk antibodies (IgY) against ND virus were immobilized on the Au electrodes (WE) using two different methods: (1) the combination protein A/glutaraldehyde (PrA/GA) and (2) the self-assembly modification of thioglycolic acid with the activation by $\mathrm{N}$-succinimidyl ester (SAM/NHS). The fabricated immunosensors were used to detect ND virus. The effect of virus incubation time on the output signal of the immunosensors and specificity and sensitivity of the ND virus immunosensors was also investigated. Both immunosensors showed advantages over conventional ones such as simple process, quick response, direct detection, high specificity and sensitivity, and potential miniaturization by integrating with micro reactors.

\section{Materials and Methods}

2.1. Chemicals. Polydimethylsiloxane (PDMS) Sylgard 184 was obtained from Dow Corning. Staphylococcal protein A (PrA), bovine serum albumin (BSA, 98\% purity), phosphate buffer solution (PBS, $0.01 \mathrm{M}, \mathrm{pH} 7.4$ ), potassium hexacyanoferrate(II) trihydrate $\left(\mathrm{K}_{4} \mathrm{Fe}(\mathrm{CN})_{6} \cdot 3 \mathrm{H}_{2} \mathrm{O}, 99.5 \%\right.$ purity), potassium ferricyanide(III) $\left(\mathrm{K}_{3} \mathrm{Fe}(\mathrm{CN})_{6}, 97 \%\right.$ purity), potassium chloride ( $\mathrm{KCl}, 99.0 \%$ purity), glutaraldehyde solution (25 wt. \% in $\mathrm{H}_{2} \mathrm{O}$ ), thioglycolic acid (TGA, 98.0\% purity), $N, N^{\prime}$-dicyclohexylcarbodiimide (DCC, $99.0 \%$ purity), $N-$ hydroxysuccinimide (NHS, 97\% purity), and N,N-dimethylformamide (DMF, $99.8 \%$ purity) were purchased from
Sigma-Aldrich. All other reagents were of analytical grade and used without further purification.

Chicken egg yolk antibodies against Newcastle disease virus (IgY, $60 \mu \mathrm{g} / \mathrm{mL}$ ) were obtained from Biotech-Vet Co. (Hanoi, Vietnam). Newcastle disease vaccine type $M$ (inactivated NDV, $10^{6}$ embryo infectious dose $50 \%$ $\left(\mathrm{EID}_{50}\right) / \mathrm{mL}$ ) was purchased from Hanvet Co. JSc. (Hanoi, Vietnam). Avian influenza virus vaccines including $\mathrm{H} 5 \mathrm{~N} 1$ subtype (inactivated AIV/H5N1 virus) and $\mathrm{H} 5 \mathrm{~N} 2$ subtype (inactivated AIV/H5N2 virus) were supplied by Joint Stock Company Central Veterinary (Hanoi, Vietnam).

2.2. Measuring Setup. The integrated Au electrodes consisted of a $1 \mathrm{~mm}$ in diameter working electrode (WE) and a counter electrode $(\mathrm{CE})$ in an $8.5 \times 12.2 \mathrm{~mm}^{2}$ chip. These electrodes were deposited on a $\mathrm{SiO}_{2} / \mathrm{Si}$ substrate by cathode sputtering technique. The detailed fabrication process was previously discussed [22]. The $(100 \mu \mathrm{m}$ in diameter) $\mathrm{Ag} / \mathrm{AgCl}$ wire, used as a quasireference electrode ( $\mathrm{qRE}$ ), was prepared by oxidizing the silver wire [23]. The three-electrode system (including qRE) is integrated with a PDMS-based microchamber in which the qRE is immersed (independently) in a $100 \mu \mathrm{L}$ open chamber (Figure 1(a)). This structure, on the one hand, reduces the microelectrode fabrication process in a clean room and, on the other hand, is convenient for electrical connection with a measuring circuit (Figure 1(b)). The system is wired with EC301 from Stanford Research Systems.

2.3. IgY Antibody Immobilization. To prepare a clean surface with ready functional groups before immobilizing IgY antibody, the integrated $\mathrm{Au}$ electrodes were pretreated in acetone, Piranha solution $\left(\mathrm{H}_{2} \mathrm{O}_{2}: \mathrm{H}_{2} \mathrm{SO}_{4}, 3: 7\right)$, and ethanol. The electrodes were then rinsed with deionized water and nitrogen dried. After that, the Au electrodes were electrochemically activated in $0.5 \mathrm{M} \mathrm{H}_{2} \mathrm{SO}_{4}$ solution by sweeping the voltage from $-0.5 \mathrm{~V}$ to $+1 \mathrm{~V}$ vs. $\mathrm{Ag} / \mathrm{AgCl}$ (in sat. $3 \mathrm{M}$ $\mathrm{KCl}$ ) at $50 \mathrm{mV} / \mathrm{s}$ until the cyclic voltammetry characteristics were stable.

Right after the surface treatment, chicken egg yolk antibodies (IgY) against ND virus were immobilized on the $\mathrm{Au}$ electrodes (WE) by two approaches, namely, protein A/glutaraldehyde (PrA/GA) and self-assembly modification/N-succinimidyl active ester (SAM/NHS). 


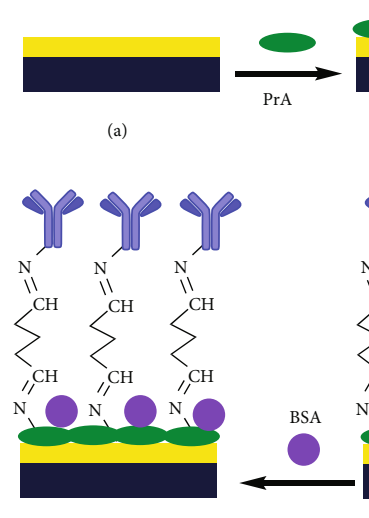

(e)

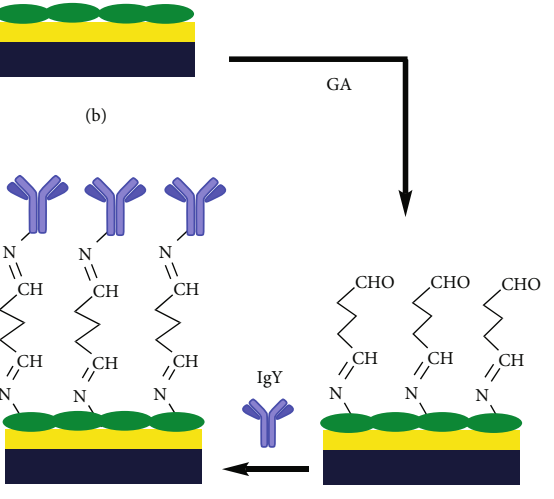

(d)

(c)

FIgURe 2: The scheme of antibody immobilization process using PrA/GA.

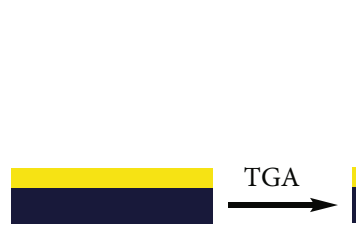

(a)

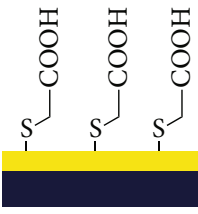

(b)
DCC+NHS

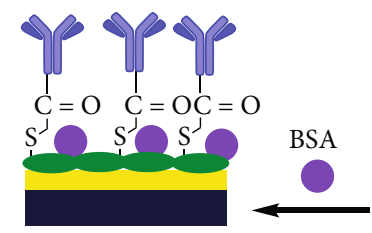

(e)

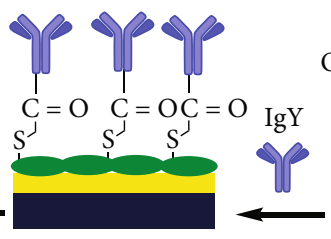

(d)

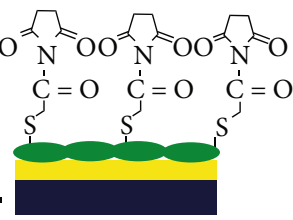

(c)

FIGURE 3: The scheme of antibody immobilization process using SAM/NHS.

\subsubsection{The Scheme of Antibody Immobilization Process Using} $\operatorname{PrA} / G A$. The scheme of antibody immobilization process using PrA/GA is shown in Figures 2(a)-2(e). Firstly, the Au working electrode (WE) was incubated with a solution of protein A ( $1 \mathrm{mg} / \mathrm{mL}$ in PBS) for 3 hours. The PrA-modified electrode was then soaked in a solution of GA (5\% wt. in deionized water) for 30 minutes. Then, IgY antibodies $(60 \mu \mathrm{g} / \mathrm{mL}$ in PBS) were immobilized on the Au WE for 3 hours at $4^{\circ} \mathrm{C}$. Lastly, BSA (1\% wt./vol. in PBS) was deposited on the WE for 30 minutes to block unbound sites. After each modified step, the WE was rinsed with PBS to remove unbound molecules. The immunosensor was stored in a refrigerator at $4^{\circ} \mathrm{C}$ for further use.

2.3.2. The Scheme of Antibody Immobilization Process Using $S A M / N H S$. The scheme of antibody immobilization process using SAM/NHS is shown in Figures 3(a)-3(e). The Au WE was incubated with ethanol solution of $10 \mathrm{mM}$ TGA for 24 hours for self-assembly modification (SAM) to occur. The excess TGA molecules on the modified WE were removed by rinsing with ethanol. The SAM-modified Au WE was treated with a DMF solution of $0.2 \mathrm{M}$ DCC and $0.1 \mathrm{M}$ NHS for $1 \mathrm{~h}$ at room temperature to convert the terminal carboxylic group to the active NHS ester. After rinsing with deionized water, the WE was incubated with $60 \mu \mathrm{g} / \mathrm{mL}$ solution (borate buffer, $\mathrm{pH}=8.2$ ) of IgY antibodies for 12 hours at $4^{\circ} \mathrm{C}$. The excess antibodies were then washed off with PBS. BSA (1\% wt./vol. in PBS) was also used to block unbound sites. Finally, the WE was rinsed with PBS, nitrogen dried, and stored at $4^{\circ} \mathrm{C}$.

2.4. Newcastle Disease Virus Detection. In the three-electrode system, the Au (WE) was prepared with IgY antibodies and the fabricated $\mathrm{Ag} / \mathrm{AgCl} \mathrm{qRE}$ was wired with the microchamber (Figure 1). ND virus was detected using the label-free electrochemical immunosensor. $20 \mu \mathrm{L}$ NDV sample (with varied concentrations of the NDV in 0.01 M PBS, pH 7.4) was injected into the microchamber. After the microchamber was incubated for 1 hour at $25^{\circ} \mathrm{C}$, it was rinsed five times with PBS buffer. Electrolyte, composed of $0.1 \mathrm{M} \mathrm{KCl}$ and $0.03 \mathrm{M}$ $\mathrm{K}_{3} \mathrm{Fe}(\mathrm{CN})_{6} / \mathrm{K}_{4} \mathrm{Fe}(\mathrm{CN})_{6}(1: 1)$ as a redox couple, was pumped into the microchamber with the rate of $100 \mu \mathrm{L} / \mathrm{min}$. Cyclic 


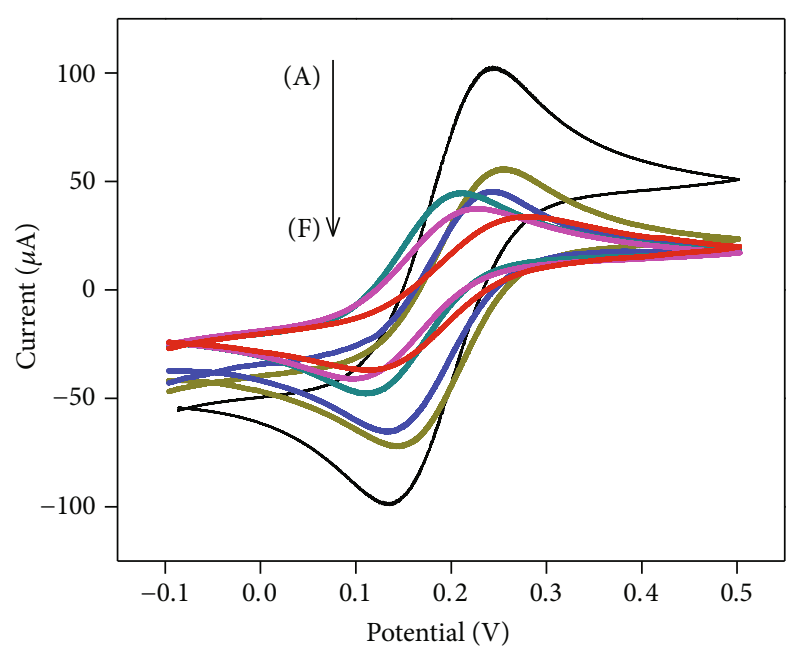

(a)

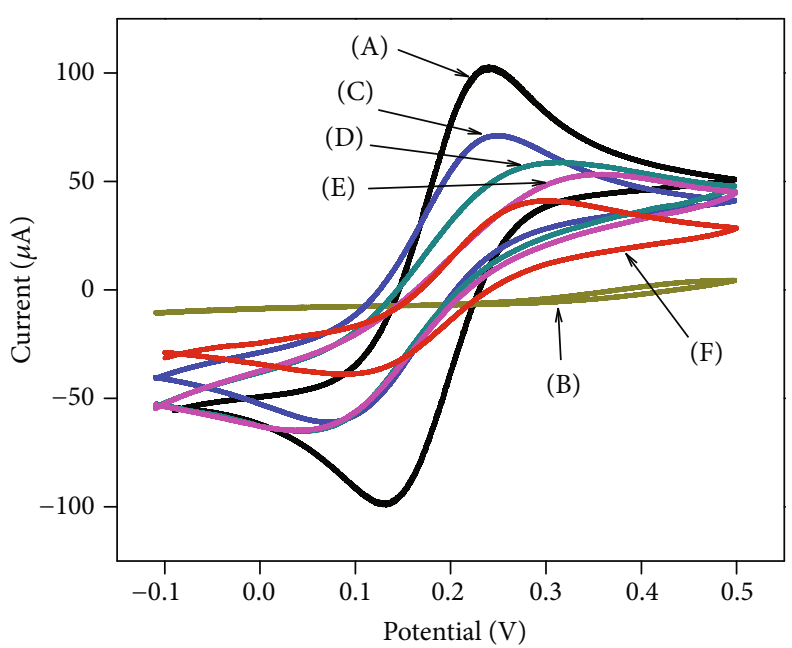

(b)

FIgURE 4: CV characterization of modified electrodes measured in the microchamber. (a) PrA/GA immunosensor: CV curve of (A) Au electrode, (B) PrA-Au electrode, (C) GA-PrA-Au electrode, (D) IgY-GA-PrA-Au electrode, and (E) BSA-IgY-GA-PrA-Au electrode and (F) after immunoreaction of $10^{4} \mathrm{EID}_{50} / \mathrm{mL}$ NDV solution with PrA/GA immunosensor. (b) SAM/NHS immunosensor: (A) Au electrode, (B) TGA-Au electrode, (C) NHS-TGA-Au electrode, (D) IgY-NHS-TGA-Au electrode, and (E) BSA-IgY-NHS-TGA-Au electrode and (F) after immunoreaction of $10^{4} \mathrm{EID}_{50} / \mathrm{mL}$ NDV solution with SAM/NHS immunosensor.

voltammetry $(\mathrm{CV})$ measurements were performed using EC301 Stanford Research Systems; the potential was cycled from -0.2 to $0.5 \mathrm{~V}$ with scan rate $25 \mathrm{mV} / \mathrm{s}$.

\section{Results and Discussion}

A cyclic voltammetry (CV) test was conducted using conventional reference electrode and the fabricated $\mathrm{Ag} / \mathrm{AgCl} \mathrm{qRE}$ (located inside the microchamber). In both cases, two peaks at $0.2 \mathrm{~V} / 0.1 \mathrm{~V}$ and $0.27 \mathrm{~V} / 0.17 \mathrm{~V}$, representing the oxidation of $\mathrm{Fe}(\mathrm{CN})_{6}{ }^{4-}$ and reduction of $\mathrm{Fe}(\mathrm{CN})_{6}{ }^{3-}$, were observed on the $\mathrm{CV}$ curves. The measured peak current $\left(I_{\text {anodic }}\right.$ and $\left.I_{\text {cathodic }}\right)$ and the difference between the anodic and cathodic peak potentials, $\Delta E$, stayed almost the same after $20 \mathrm{CV}$ cycles (detail was described in supplemental data).

3.1. Immobilization of the IgY Antibody from Chicken Egg Yolk on the Au Electrode. Figure 4 shows CV characteristics of the WE measured in $\mathrm{Fe}(\mathrm{CN})_{6}{ }^{3-/ 4-}$ solution with different IgY antibody immobilization step for PrA/GA immunosensor (Figure 4(a)) and SAM/NHS immunosensor (Figure 4(b)). The difference in the current peak $\left(I_{\text {peak }}=I_{\text {anodic }}-I_{\text {cathodic }}\right)$ was used to demonstrate the formation of the layers of the immunosensor during stepwise modification procedures (see Table S1 in supplemental information).

3.1.1. Antibody Immobilization Using PrA/GA Approach. As observed in Figure $4(\mathrm{a})$, the highest $I_{\text {peak }}(202.8 \mu \mathrm{A})$ on the $\mathrm{CV}$ curve obtained with the bare Au electrode due to high conductivity and low barrier of gold metal makes it easy for electron transfer. The adsorption of protein $\mathrm{A}$ on the Au surface formed an insulating layer that reduces electron transfer leading to a lower peak current of the $\mathrm{Au} / \mathrm{PrA}$ electrode $\left(I_{\text {peak,Au/PrA }}=129.2 \mu \mathrm{A}\right)$. The attachment of glutaraldehyde linkers onto the $\operatorname{PrA} / \mathrm{Au}$ electrode also resulted in a reduction of $I_{\text {peak }}\left(I_{\text {peak }, \mathrm{Au} / \mathrm{PrA} / \mathrm{GA}}=110.0 \mu \mathrm{A}\right)$. Glutaraldehyde plays a cross-linking role between protein $\mathrm{A}$ and $\operatorname{IgY}$ antibody through the formation of imine bonds $(\mathrm{C}=\mathrm{N}$ bonds) between $-\mathrm{CHO}$ groups and $-\mathrm{NH}_{2}$ groups as shown in Figure 2. The immobilization of $\operatorname{IgY}$ antibodies caused a further decrease in $I_{\text {peak }}\left(I_{\text {peak }, \mathrm{Au} / \mathrm{PrA} / \mathrm{GA} / \mathrm{IgY}}=99.0 \mu \mathrm{A}\right)$.

The above discussion revealed that the binding of IgY antibodies on the surface of immunosensor leads to an increase in the charge transfer resistance of $\mathrm{Fe}(\mathrm{CN})_{6}{ }^{3-14-}$ redox couple to the $\mathrm{Au}$ electrode, thereby reducing the peak current. When the WE was deposited with BSA for blocking unbound sites and the IgY antibody was immobilized on the Au electrode, a slight decrease in the peak current was also observed $\left(I_{\text {peak }, \text { PrA-GA immunosensor }}=87.3 \mu \mathrm{A}\right)$.

3.1.2. Antibody Immobilization Using SAM/NHS Approach. As shown in Figure 3(b), a self-assembled modification (SAM) of TGA is formed on the Au electrode surface through the strong gold-thiolate bonds leading to the formation of a highly insulating surface layer that blocks almost all the faradic currents $[24,25]$. That is why no (current) peak on the curve (B) was observed (Figure 4(b)). The reason for this is that the negatively charged terminal carboxyl groups of TGA (formed by the deprotonation in aqueous solution) prevent the transfer of negative $\mathrm{Fe}(\mathrm{CN})_{6}^{3-14-}$ redox couple to the electrode surface creating a depleted layer between the sensor surface and solution. If the TGA layer is activated by DCC and NHS, it forms an NHS ester and the negatively charged carboxyl groups of TGA are replaced by the neutrally charged NHS esters as shown in Figure 3(c). Thus, the transfer of the negative $\mathrm{Fe}(\mathrm{CN})_{6}{ }^{3-14-}$ redox couple to the electrode surface makes it advantageous for the current to 


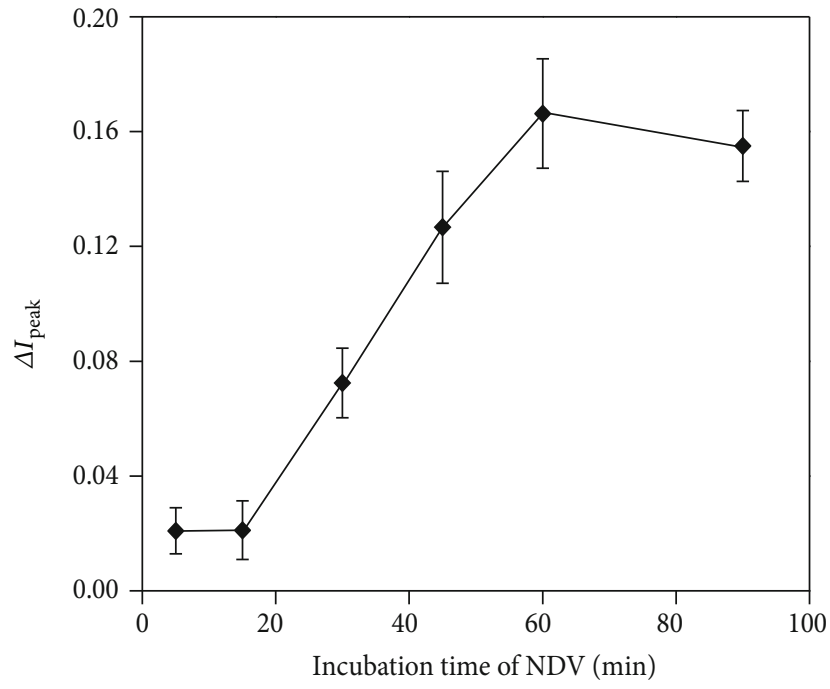

(a)

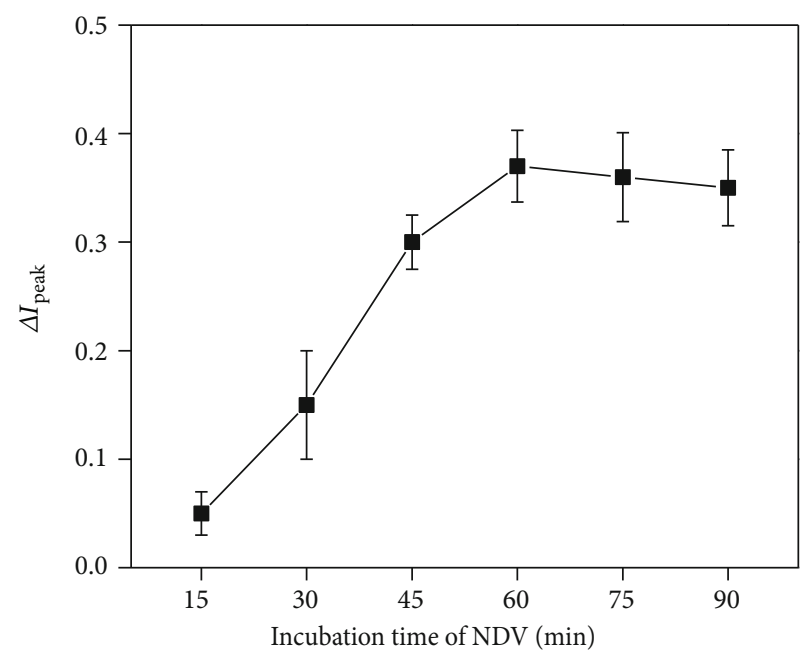

(b)

FIGURE 5: The output signal of immunosensor depends on incubation time: (a) PrA/GA immunosensor (with $10^{6} \mathrm{EID}_{50} / \mathrm{mL} \mathrm{NDV}$ and (b) $\mathrm{SAM} / \mathrm{NHS}$ immunosensor (with $10^{2} \mathrm{EID}_{50} / \mathrm{mL} \mathrm{NDV}$ ).

flow. As a result, the current density is increased as illustrated in Figure $4(\mathrm{~b})(\mathrm{C})\left(I_{\text {peak,Au/TGA/DCC }+\mathrm{NHS}}=132.29 \mu \mathrm{A}\right)$.

The immobilization of IgY antibodies on the immunosensor's surface in which active NHS ester is replaced by the amine groups of anti-NDV IgY (Figure 3(d)) leads to an increase in the charge transfer resistance of $\mathrm{Fe}(\mathrm{CN})_{6}^{3-/ 4-}$ redox couple to the Au electrode, thereby reducing the peak current $\left(I_{\text {peak,Au/TGA/DCC+NHS/IgY }}=124.75 \mu \mathrm{A}\right)$. When the WE was deposited with BSA for blocking unbound sites, a further slight decrease in the peak current was also observed in Figure 4(b) (E) $\left(I_{\text {peak }, \text { SAM-NHS immunosensor }}=116.7 \mu \mathrm{A}\right)$. The two immobilization methods of IgY antibodies on the Au electrode exhibit good repeatability that are demonstrated by small deviation values of $I_{\text {peak,immunosensor }}$ (as shown in Figure S2 of supplemental data).

3.2. Newcastle Disease Virus Detection. The current response of immunosensors after reaction with NDV was also characterized by $\mathrm{CV}$ measurements in $\mathrm{K}_{3} \mathrm{Fe}(\mathrm{CN})_{6} / \mathrm{K}_{4} \mathrm{Fe}(\mathrm{CN})_{6}$ solution with a scan rate of $25 \mathrm{mV} / \mathrm{s}$ and shown as each curve (F) in Figure 4(a) (PrA/GA immunosensor) and Figure 4(b) (SAM/NHS immunosensor).

As observed in Figure 4(a), in the case of PrA/GA immunosensor, when specific antibody-virus interaction occurred on the surface of the immunosensor, the peak current

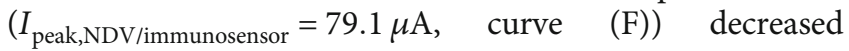
compared to that of the immunosensor without biological interactions $\left(I_{\text {peak,immunosensor }}=88.2 \mu \mathrm{A}\right.$, curve $\left.(\mathrm{E})\right)$. Performing the same experiment using the SAM/NHS immunosensor (Figure 4(b)), one could obtain the similar result. The peak current $\left(I_{\text {peak,NDV/immunosensor }}=60.3 \mu \mathrm{A}\right.$, curve $\left.(\mathrm{F})\right)$, given by the interaction between specific antibody and virus that occurred on the surface of the immunosensor, was smaller than that with no biological interactions
$\left(I_{\text {peak,immunosensor }}=116.7 \mu \mathrm{A}\right.$, curve $\left.(\mathrm{E})\right)$. The above results could explain that NDV are bound on the surface of the immunosensor based on specific antibody-virus interaction and therefore inhibiting the charge transfer process of $\mathrm{Fe}(\mathrm{CN})_{6}{ }^{3-14-}$ redox couple to the $\mathrm{Au}$ electrode surface, resulting in a decrease in current response.

The output signal of the immunosensor is calculated by the following equation:

$$
\Delta I_{\text {peak }}=\frac{I_{\text {peak }}(0)-I_{\text {peak }}(i)}{I_{\text {peak }}(0)},
$$

where $I_{\text {peak }}(0)$ is the $I_{\text {peak }}$ of the immunosensor treated with $0 \mathrm{EID}_{50} / \mathrm{mL} \mathrm{NDV}$ (in $0.01 \mathrm{M} \mathrm{PBS}, \mathrm{pH}=7.4$ ), and $I_{\text {peak }}(i)$ is the $I_{\text {peak }}$ of the immunosensor obtained after incubating with a certain NDV sample.

3.3. Effect of Virus Incubation Time on the Output Signal of the Immunosensors. In both cases of PrA/GA immunosensors and SAM-NHS immunosensors, the current responses increase accordingly with the incubation time and $\Delta I_{\text {peak }}$ reaches its maximum value $\left(\Delta I_{\text {peak }}=0.166\right.$ and $\Delta I_{\text {peak }}=$ 0.370 , respectively) at 60 minutes for the immunoreaction (Figures 5(a) and 5(b)). Further increase in incubation time did not cause significant change in $\Delta I_{\text {peak }}$ for both types of immunosensors.

$$
\text { IgY Antibody + Antigen (ND Virus) } \rightarrow \text { Immune complex }
$$

This is due to the nonlinear kinetic of the reversible immunoreaction as shown below that reaches its fastest rate of the association in the first hour [26]. Therefore, for further experiments, $60 \mathrm{~min}$ is selected as the virus incubation time for both types of immunosensors. 


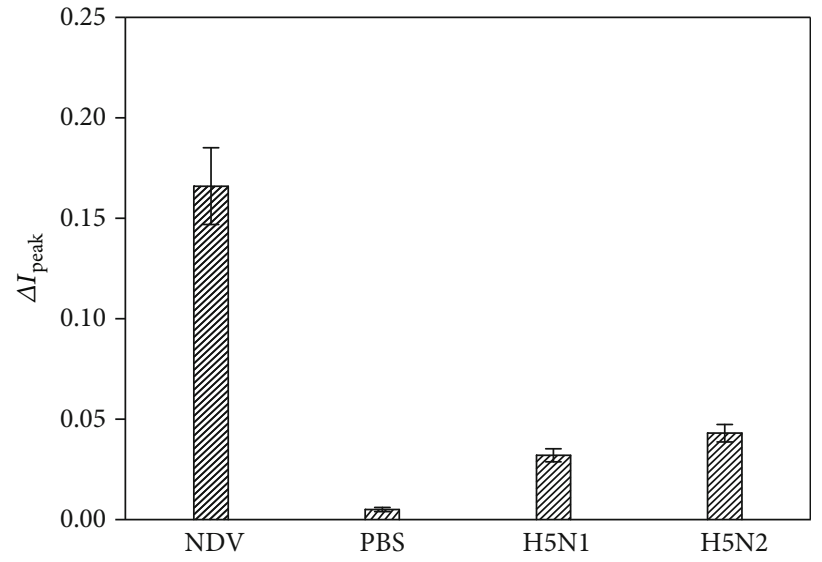

(a)

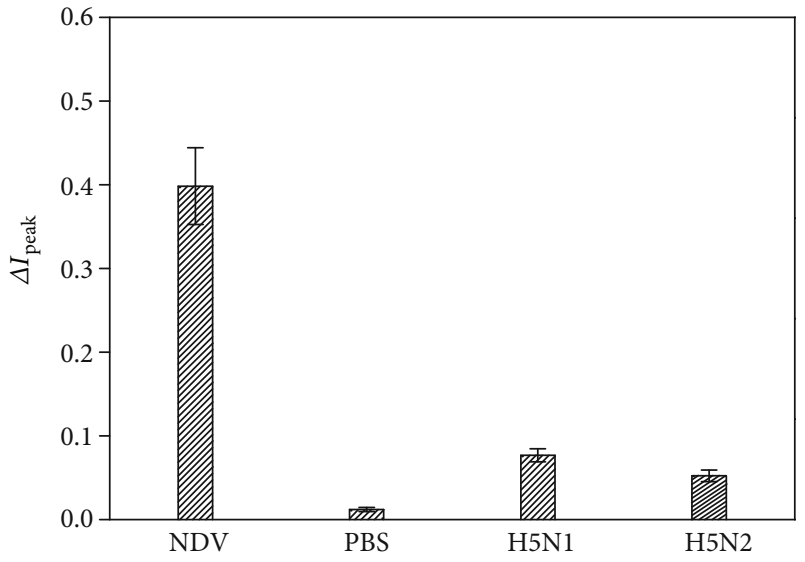

(b)

FIgure 6: Specificity of the PrA/GA (a) and SAM/NHS (b) immunosensors for NDV detection. The output signals, $\Delta I_{\text {peak }}$, of the immunosensors induced by $10^{2} \mathrm{EID}_{50} / \mathrm{mL} \mathrm{NDV}$ and nonspecific samples such as $0.01 \mathrm{M} \mathrm{PBS}(\mathrm{pH}=7.4), 10^{2} \mathrm{EID} \mathrm{D}_{5} / \mathrm{mL}$ AIV/H5N1, and $10^{2} \mathrm{EID}_{50} / \mathrm{mL}$ AIV/H5N2.

3.4. Specificity of the ND Virus Immunosensors. In order to evaluate the specificity of the PrA/GA and SAM/NHS immunosensors for the detection of NDV, $\Delta I_{\text {peak }}$ induced by PBS as the blank and several nonspecific viruses was measured. Nonspecific viruses, including $\mathrm{H} 5 \mathrm{~N} 1$ and H5N2 avian influenza A virus, and specific NDV were all prepared in $10^{2} \mathrm{EID}_{50} / \mathrm{mL}$. The immunoreactions were carried out with NDV, PBS, AIV/H5N1, and AIV/H5N2 samples for $1 \mathrm{~h}$ at $25^{\circ} \mathrm{C}$ in the microchamber. The specificity of the PrA/GA and SAM/NHS immunosensors for the NDV is exhibited in Figures 6(a) and 6(b). No obvious $\Delta I_{\text {peak }}$ response could be found under the blank (PBS). Similarly, at the same concentration, $\Delta I_{\text {peak }}$ obtained in the NDV measurement was much higher than that in cases of AIV/H5N1 and of AIV/H5N2. This implies that only the interaction between IgY antibody and NDV can cause significant current changes, another way to say that the developed PrA/GA and SAM/NHS immunosensors offer a good specificity to NDV.

3.5. Sensitivity of the ND Virus Immunosensors. To determine the sensitivity of the fabricated immunosensors, various samples of inactivated NDV with concentrations varying from $10^{2}$ to $10^{6} \mathrm{EID}_{50} / \mathrm{mL}$ (in $0.01 \mathrm{M} \mathrm{PBS}, \mathrm{pH}=$ 7.4) were tested. For each NDV concentration, five CV measurements were performed similarly using five immunosensors. The standard deviation of the measurements is calculated by the following formula:

$$
S=\sqrt{\frac{1}{(N-1)} \sum_{i=1}^{N}\left[(\Delta I)_{i}-\overline{(\Delta I)}\right]^{2}},
$$

where $N$ is the number of measurements corresponding to $N$ immunosensors; $(\Delta I)_{i}$ is the output signal of the $i^{\text {th }}$ immunosensor; $\overline{(\Delta I)}$ is the average value of $N \Delta I$ values corresponding to $N$ immunosensors; $S$ is the real standard deviation (the absolute deviation), and $(S / \overline{\Delta I}) \times 100(\%)$ is the relative standard deviation.

After acquiring and processing the data, the calibration curves for both corresponding to the two types of fabricated immunosensors that express the relationship between $\Delta I_{\text {peak }}$ and the logarithm of $\mathrm{ND}$ virus concentration are presented in Figure 7. As shown in Figure 7, both types of immunosensors showed the linear relationship between $\Delta I_{\text {peak }}$ and $\log \left[\mathrm{C}_{\mathrm{NDV}}\right]$ in the range of $10^{2} \mathrm{EID}_{50} / \mathrm{mL}-10^{6} \mathrm{EID}_{50} / \mathrm{mL}$ NDV. The linear regression equation of the PrA/GA immunosensor was $\Delta I_{\text {peak }}=$ $0.0289 \times \log \left[\mathrm{C}_{\mathrm{NDV}}\right]-0.0099 \quad\left(R^{2}=0.983\right)$ and that of the SAM/NHS immunosensor was $\Delta I_{\text {peak }}=0.0588 \times \log$ $\left[\mathrm{C}_{\mathrm{NDV}}\right]+0.261\left(R^{2}=0.991\right)$. The calibration curve corresponding to the SAM/NHS immunosensor exhibited a higher slope value and $\Delta I_{\text {peak }}$ values at each concentration than those of the PrA/GA immunosensor.

According to Swartz [27], the limit of detection (LOD) and the limit of quantification (LOQ) can be calculated using the following equations:

$$
\begin{aligned}
& \mathrm{LOD}=\frac{3.3 \times \sigma}{S}, \\
& \mathrm{LOQ}=\frac{10 \times \sigma}{S},
\end{aligned}
$$

where $\sigma$ is the standard deviation of the response $y$-intercept of the regression line and $S$ is the slope of the calibration curve. Table 1 shows the crucial parameters obtained from the two calibration curves corresponding to the two types of electrochemical label-free immunosensors. The LOD and LOQ were $10^{0.95} \mathrm{EID}_{50} / \mathrm{mL}$ and $10^{2.88} \mathrm{EID}_{50} / \mathrm{mL}$ in the case of PrA/GA immunosensor and $10^{0.67} \mathrm{EID}_{50} / \mathrm{mL}$ and $10^{2.03} \mathrm{EID}_{50} / \mathrm{mL}$ in the case of SAM/NHS immunosensor, respectively. It can be explained that, at the same measuring conditions and immune reaction (temperature, $\mathrm{pH}$, incubation time, etc.), due to the formation of stable covalent bonds, 


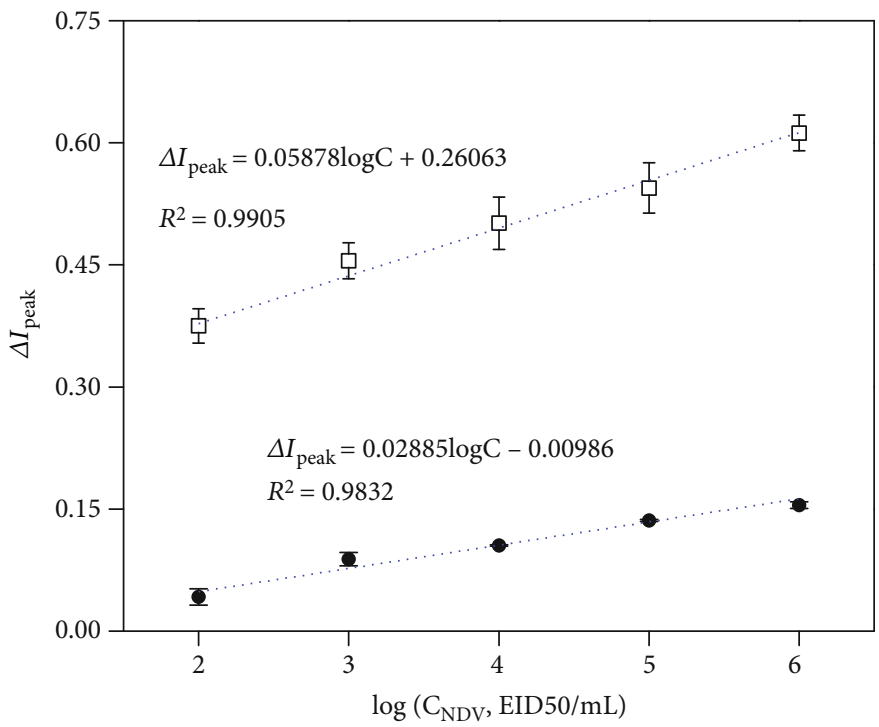

- PrA-GA immunosensor

$\square$ SAM-NHS immunosensor

FIGURE 7: $\Delta I_{\text {peak }}$ is a function of NDV concentrations.

TABLE 1: The crucial parameters of the two types of electrochemical label-free immunosensors.

\begin{tabular}{lcc}
\hline Parameter & PrA/GA immunosensor & SAM/NHS immunosensor \\
\hline Linear range of concentration & $10^{2}-10^{6} \mathrm{EID}_{50} / \mathrm{mL}$ & $10^{2}-10^{6} \mathrm{EID}_{50} / \mathrm{mL}^{-}$ \\
Correlation coefficient $\left(R^{2}\right)$ & 0.983 & 0.991 \\
Slope $(S)$ & 0.0289 & 0.0588 \\
Standard deviation of the slope $\left(\mathrm{SD}_{\mathrm{S}}\right)$ & 0.00188 & 0.00286 \\
$y$-intercept $\left(y_{\mathrm{i}}\right)$ & -0.0099 & 0.2606 \\
Standard deviation of the $y$-intercept $(\sigma)$ & 0.0080 & 0.0119 \\
LOD & $0.95\left(9 \mathrm{EID}_{50} / \mathrm{mL}\right)$ & $0.67(5 \mathrm{EID}$ \\
LOQ & $2.88\left(10^{2.88} \mathrm{EID}_{50} / \mathrm{mL}\right)$ & $2.03\left(10^{2.03} \mathrm{EID}_{50} / \mathrm{mL}^{2}\right)$ \\
\hline
\end{tabular}

TABLE 2: Comparison of analytical properties of different methods for the detection of NDV.

\begin{tabular}{|c|c|c|c|c|c|c|}
\hline Technique & Immobilization & Type & Antibody & Virus & Limit of detection & Ref. \\
\hline Optic & APTES/CDI & Indirect & Goat monoclonal IgY & Purified NDV & $2 \mathrm{ng} / \mathrm{mL}$ & [30] \\
\hline RT-PCR & & & & Inactivated NDV & $5 \times 10^{2} \mathrm{ELD}_{50} / \mathrm{mL}$ & [31] \\
\hline RT-PCR & & & & Inactivated NDV & $5 \times 10^{2} \mathrm{ELD}_{50} / \mathrm{mL}$ & {$[5]$} \\
\hline RT-PCR & & & & Inactivated NDV & $10^{5.8} \mathrm{ELD}_{50} / \mathrm{mL}$ & {$[6]$} \\
\hline RRT-PCR & & & & NDV RNA & $10 \mathrm{EID}_{50} / \mathrm{mL}$ & {$[1]$} \\
\hline $\mathrm{CV}$ & $\operatorname{PrA} / G A$ & Direct & $\operatorname{IgY}$ & Inactivated NDV & $9 \mathrm{EID}_{50} / \mathrm{mL}$ & \multirow{2}{*}{ This work } \\
\hline $\mathrm{CV}$ & SAM/NHS & Direct & $\operatorname{IgY}$ & Inactivated NDV & $5 \mathrm{EID}_{50} / \mathrm{mL}$ & \\
\hline
\end{tabular}

NDV: Newcastle disease virus; EID: embryo infectious dose; ELD: embryo lethal dose; RT-PCR: reverse transcriptase-polymerase chain reaction; RRT-PCR: real-time reverse transcription PCR.

the density of specific antibodies bound on the SAM/NHS immunosensor's surface is higher than that of the PrA/GA immunosensor. Moreover, the insulating property of PrA that influences the formation of the antibody-antigen complex partly contributes to lowering sensitivity of the PrA/GA immunosensor as compared to the SAM/NHS immunosensor.
Table 2 summarizes some analytical properties of different methods for the detection of NDV. The limits of detection values of the two types of electrochemical label-free immunosensors were comparable to those of the PCR. Moreover, the fabricated immunosensors also showed advantages over conventional ones such as simple process, do not require clean room facilities, quick response, direct detection, 
and potential miniaturization by integrating with micro reactors (100 $\mu \mathrm{L}-1 \mathrm{~mL}$ in volume) which may be suitable for future on-site and in-field measurements. In particular, in this work, the chicken egg yolk antibody (IgY) was used as the biological recognition element of the immunosensor instead of using IgG antibody (monoclonal and polyclonal antibody) $[16,28,29]$ which requires modern techniques and expensive biologicals and goes through many steps with complicated procedure $[19,20]$.

The study about using chicken egg yolk antibody (IgY) as the biological recognition element of the immunosensor may not only reduce analysis costs but also provide an effective solution to detect immediately virus in outbreaks of infectious diseases.

\section{Conclusions}

The integrated three-electrode system using fabricated $\mathrm{Ag} / \mathrm{AgCl}$ electrode as $\mathrm{qRE}$ and the microchamber not only simplifies the microelectrode fabrication process in a clean room and reduces the analytical volume but also increases accuracy by enhancing the signal-to-noise ratio and thereby improving the sensitivity of electrochemical immunosensors. The IgY was used as the biological recognition element to replace purified IgG antibody that requires a complex extraction process and is time-consuming. The IgY against NDV was immobilized on the Au electrodes (WE) using PrA/GA and SAM/NHS approaches. Both immunosensors offer linear relationship with $\log \left[\mathrm{C}_{\mathrm{NDV}}\right]$ in the range of $10^{2} \mathrm{EID}_{50} / \mathrm{mL}-10^{6} \mathrm{EID}_{50} / \mathrm{mL}$ NDV. The fabricated immunosensors showed advantages over conventional ones such as simple process, do not require clean room facilities, quick response, direct detection, and potential miniaturization by integrating with micro reactors $(100 \mu \mathrm{L}-1 \mathrm{~mL}$ in volume) which may be suitable for future on-site and in-field measurements.

\section{Data Availability}

The data used to support the findings of this study are included within the article and the supplementary information file.

\section{Conflicts of Interest}

The authors declare that there is no conflict of interest regarding the publication of this paper.

\section{Acknowledgments}

This research is supported by the Vietnamese Ministry of Education and Training (MOET) under grant number B2015-01-102.

\section{Supplementary Materials}

A supplementary file is submitted along with the manuscript. In this file, Figure $\mathrm{S} 1$ shows the $\mathrm{CV}$ measured in $\mathrm{Fe}(\mathrm{CN})_{6}{ }^{3-/ 4-}$ solution at a $25 \mathrm{mV} / \mathrm{s}$ scan rate of the three-electrode system in the open cell using $\mathrm{Ag} / \mathrm{AgCl}$ (in sat. $3 \mathrm{M} \mathrm{KCl}$ ) conventional
RE (curve a) and inside the microchamber using fabricated $\mathrm{Ag} / \mathrm{AgCl}$ electrode as qRE (curve b). Besides, Table S1 shows the difference in the current peak $\left(I_{\text {peak }}=I_{\text {anodic }}-I_{\text {cathodic }}\right)$ that was used to demonstrate the formation of the layers of the immunosensor during stepwise modification procedures. Finally, Figure S2 and Table S2 present the average values and the standard deviations of $I_{\text {peak }}$ of six bare Au electrodes, six PrA/GA immunosensors, and six SAM/NHS immunosensors. (Supplementary Materials)

\section{References}

[1] T. Farkas, É. Székely, S. Belák, and I. Kiss, "Real-time PCR-based pathotyping of Newcastle disease virus by use of TaqMan minor groove binder probes," Journal of Clinical Microbiology, vol. 47, no. 7, pp. 2114-2123, 2009.

[2] H. Chaka, P. N. Thompson, F. Goutard, and V. Grosbois, "Evaluation of enzyme-linked immunosorbent assays and a haemagglutination inhibition tests for the detection of antibodies to Newcastle disease virus in village chickens using a Bayesian approach," Preventive Veterinary Medicine, vol. 119, no. 1-2, pp. 21-30, 2015.

[3] J. J. de Wit, F. G. Davelaar, and W. W. Braunius, "Comparison of the enzyme linked immunosorbent assay, the haemagglutination inhibition test and the agar gel precipitation test for the detection of antibodies against infectious bronchitis and Newcastle disease in commercial broilers," Avian Pathology, vol. 21, no. 4, pp. 651-658, 1992.

[4] G. Thirumurugan, R. Jayakumar, K. Kumanan, A. T. Venugopalan, and K. Nachimuthu, "Latex immunoassay for rapid detection of Newcastle disease virus," Tropical Animal Health and Production, vol. 29, no. 4, pp. 227-230, 1997.

[5] S. G. Daniela, T. Barbara, and M. A. Hofmann, "Detection of Newcastle disease virus in organs and faeces of experimentally infected chickens using RT-PCR," Avian Pathology, vol. 29, no. 2, pp. 143-152, 2000.

[6] F. Perozo, P. Villegas, C. Estevez, I. Alvarado, and L. B. Purvis, "Use of FTA filter paper for the molecular detection of Newcastle disease virus," Avian Pathology, vol. 35, no. 2, pp. 9398, 2006.

[7] H. Y. Wu, S. H. Chiou, J. H. Shien, P. C. Chang, and H. K. Shieh, "Detection of proteins and nucleic acids of Newcastle disease virus in Eimeria acervuline," Avian Pathology, vol. 28, no. 5, pp. 441-445, 1999.

[8] P. Skládal, "Advances in electrochemical immunosensors," Electroanalysis, vol. 9, no. 10, pp. 737-745, 1997.

[9] R. Wang, J. Lin, K. Lassiter et al., "Evaluation study of a portable impedance biosensor for detection of avian influenza virus," Journal of Virological Methods, vol. 178, no. 1-2, pp. 52-58, 2011.

[10] J. Heo and S. Z. Hua, "An overview of recent strategies in pathogen sensing," Sensors, vol. 9, no. 6, pp. 4483-4502, 2009.

[11] B. Pejcic, R. De Marco, and G. Parkinson, "The role of biosensors in the detection of emerging infectious diseases," Analyst, vol. 131, no. 10, pp. 1079-1090, 2006.

[12] Y. Wang, Q. He, Y. Dong, and H. Chen, "In-channel modification of biosensor electrodes integrated on a polycarbonate microfluidic chip for micro flow-injection amperometric determination of glucose," Sensors and Actuators B: Chemical, vol. 145, no. 1, pp. 553-560, 2010. 
[13] P. He, Z. Wang, and W. Yang, "Development of a label-free electrochemical immunosensor based on carbon nanotube for rapid determination of clenbuterol," Food Chemistry, vol. 112, no. 3, pp. 707-714, 2009.

[14] J. Wu, R. Wang, H. Yu et al., "Inkjet-printed microelectrodes on PDMS as biosensors for functionalized microfluidic systems," Lab on a Chip, vol. 15, no. 3, pp. 690-695, 2015.

[15] T. L. Tran, T. X. Chu, P. Q. Do et al., "In-channel-grown polypyrrole nanowire for the detection of DNA hybridization in an electrochemical microfluidic biosensor," Journal of Nanomaterials, vol. 2015, 7 pages, 2015.

[16] R. Wang, Y. Wang, K. Lassiter et al., "Interdigitated array microelectrode based impedance immunosensor for detection of avian influenza virus H5N1," Talanta, vol. 79, no. 2, pp. 159-164, 2009.

[17] J. Lum, R. Wang, K. Lassiter et al., "Rapid detection of avian influenza $\mathrm{H} 5 \mathrm{~N} 1$ virus using impedance measurement of immuno-reaction coupled with RBC amplification," Biosensors \& Bioelectronics, vol. 38, no. 1, pp. 67-73, 2012.

[18] J. Zhou, L. Du, L. Zou, Y. Zou, N. Hu, and P. Wang, “An ultrasensitive electrochemical immunosensor for carcinoembryonic antigen detection based on staphylococcal protein $\mathrm{A}-\mathrm{Au}$ nanoparticle modified gold electrode," Sensors and Actuators B: Chemical, vol. 197, pp. 220-227, 2014.

[19] M. Page and R. Thorpe, "Purification of IgG using protein A or protein G," in The Protein Protocols Handbook, J. M. Walker, Ed., pp. 993-994, Humana Press, Totowa, NJ, 2nd Edition edition, 2002.

[20] P. J. Conroy, S. Hearty, P. Leonard, and R. J. O'Kennedy, "Antibody production, design and use for biosensor-based applications," Seminars in Cell \& Developmental Biology, vol. 20, no. 1, pp. 10-26, 2009.

[21] T. Quang Thinh, T. Van Vu Quan, L. B. Dương, T. H. Thuy, C. T. Xuan, and M. Anh Tuan, "A label-free electrochemical immunosensor for detection of Newcastle disease virus," IFMBE Proceedings, 7th International Conference on the Development of Biomedical Engineering in Vietnam (BME7), vol. 69, pp. 699-703, Springer, Singapore, BME 2018.

[22] T. L. Tran, T. X. Chu, D. C. Huynh, D. T. Pham, T. H. T. Luu, and A. T. Mai, "Effective immobilization of DNA for development of polypyrrole nanowires based biosensor," Applied Surface Science, vol. 314, pp. 260-265, 2014.

[23] Y. Bi and J. Ye, "In situ oxidation synthesis of $\mathrm{Ag} / \mathrm{AgCl}$ coreshell nanowires and their photocatalytic properties," Chemical Communications, vol. 2009, no. 43, pp. 6551-6553, 2009.

[24] S. J. Ding, B. W. Chang, C. C. Wu, M. F. Lai, and H. C. Chang, "Impedance spectral studies of self-assembly of alkanethiols with different chain lengths using different immobilization strategies on Au electrodes," Analytica Chimica Acta, vol. 554, no. 1-2, pp. 43-51, 2005.

[25] A. Tlili, A. Abdelghani, S. Hleli, and M. Maaref, "Electrical characterization of a thiol SAM on gold as a first step for the fabrication of immunosensors based on a quartz crystal microbalance," Sensors, vol. 4, no. 6, pp. 105-114, 2004.

[26] R. Reverberi and L. Reverberi, "Factors affecting the antigenantibody reaction," Blood Transfusion, vol. 5, pp. 227-240, 2007.

[27] M. Swartz, Handbook of Analytical Validation, CRC Press, 2012.

[28] B. Byrne, E. Stack, N. Gilmartin, and R. O’Kennedy, “Antibody-based sensors: principles, problems and potential for detection of pathogens and associated toxins," Sensors, vol. 9, no. 6, pp. 4407-4445, 2009.

[29] C. Ding, H. Li, K. Hu, and J.-M. Lin, "Electrochemical immunoassay of hepatitis B surface antigen by the amplification of gold nanoparticles based on the nanoporous gold electrode," Talanta, vol. 80, no. 3, pp. 1385-1391, 2010.

[30] L. E. William and T. H. Gail, "Detection of Newcastle disease virus using an evanescent wave immuno-based biosensor," Canadian Journal of Chemistry, vol. 74, no. 5, pp. 707-712, 1996.

[31] S. Norbert, B. Katrin, L. Bruckner, and H. A. Martin, "Detection of Newcastle disease virus in poultry vaccines using the polymerase chain reaction and direct sequencing of amplified cDNA," Vaccine, vol. 13, no. 4, pp. 360-364, 1995. 


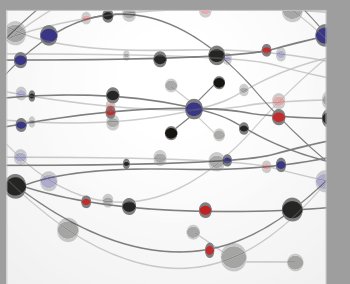

The Scientific World Journal
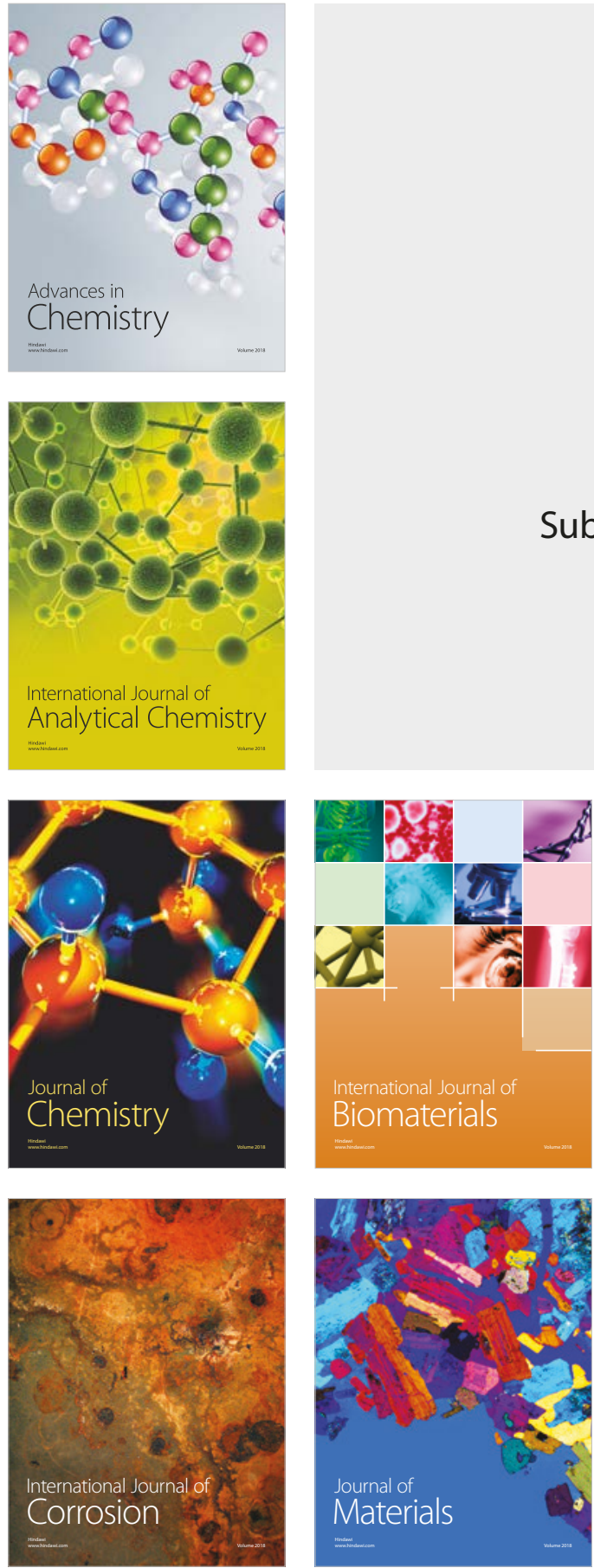

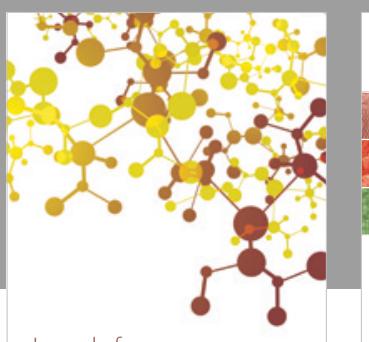

Journal of

Applied Chemistry
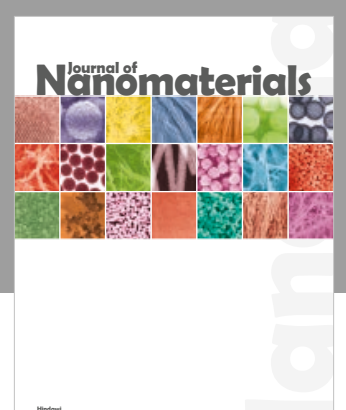

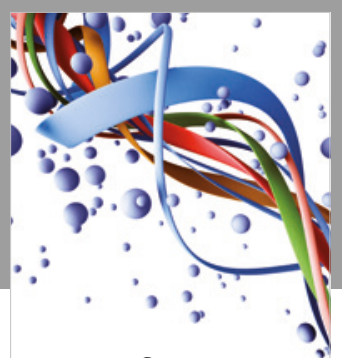

Scientifica

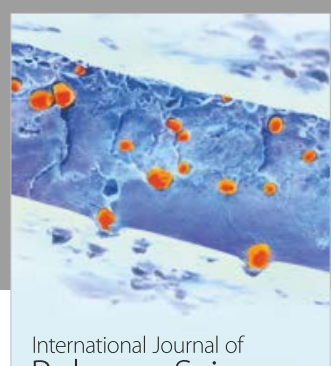

Polymer Science

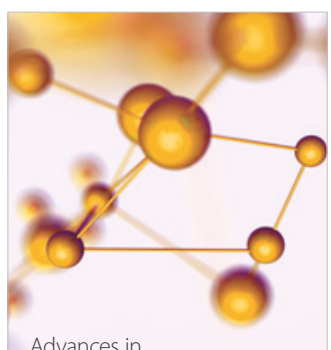

Physical Chemistry
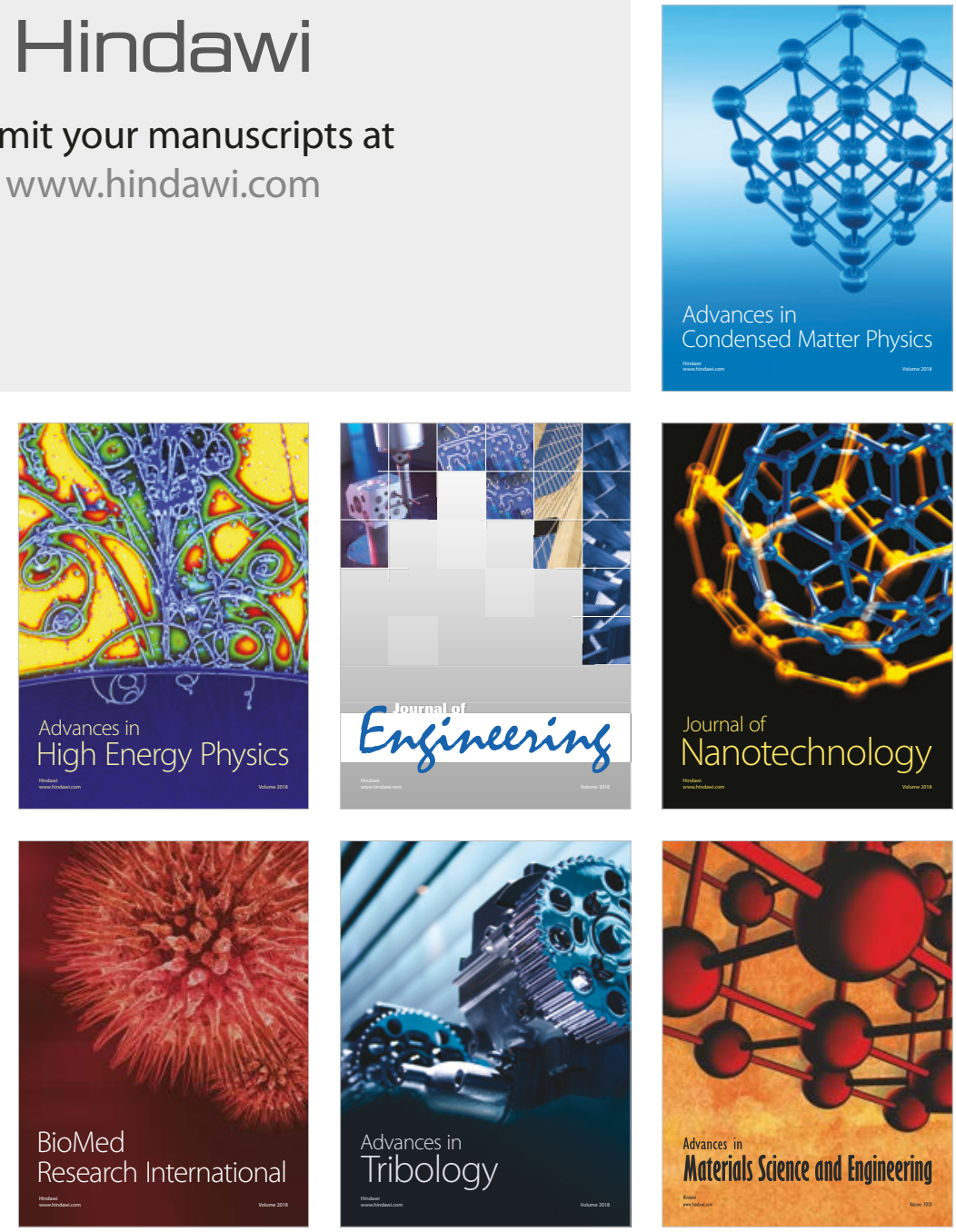